\title{
Research on the Present Situation, Problems and Countermeasures of Network Accounting
}

\author{
Yuejun $\mathrm{Tu}^{1, \mathrm{a}}$, Jianhua $\mathrm{Du}^{2, \mathrm{~b}}$ \\ ${ }^{12}$ Nanchang Institute of Science \& Technology, Nanchang, Jiangxi, 330000 \\ ${ }^{\mathrm{a}}$ email, ${ }^{\mathrm{b}}$ email
}

Keywords: Network Accounting; Status Quo; Problem; Solution

\begin{abstract}
With the advent of the information age, the computer as a medium of information processing and effective tools, applied to all walks of life in the daily work. Network accounting is the inevitable trend of the entire network environment, is the combination of traditional accounting and network products. Network accounting is the inheritance of traditional accounting, but also the development of traditional accounting. Chinese network accounting development is still in the initial stage, the development of network accounting waiting for our lives and work to bring convenience at the same time also produced some security risks. This paper will elaborate the definition and characteristics of network accounting, analyze the status quo of network accounting and its existing problems, and finally put forward the relevant countermeasures.
\end{abstract}

\section{Introduction}

Network accounting is a kind of accounting activity that depends on network technology to confirm, measure and publish various transactions and events. Based on the background of the Internet, network accounting is one of the most important components of e-commerce. Network accounting promotes the docking of financial systems and business in the process of e-commerce, such as long-distance financial affairs such as remote reports, reimbursement, audit and auditing, At the same time, network accounting can handle dynamic accounting, to achieve online financial management. Network accounting changes the way that traditional accounting access to financial information and the use of financial information in the form of support for electronic documents and electronic money, to promote the accounting work of large enterprises to paperless process.

\section{The Status of Network Accounting and Its Problems}

The network has the advantages and disadvantages of the accounting system. When the enterprise is looking for the accounting information or carrying out the related economic activities in the network, the network provides the resources for it, but also puts it at the risk level. There are two kinds of risk of enterprise network accounting system. First, the risk of leakage, that is, unauthorized personnel to invade the enterprise network accounting system, want to steal the business secrets, resulting in huge loss of corporate property; second, the risk of malicious attacks Network hackers deliberately implanted the virus into the enterprise network accounting system, undermining the normal operation of the network accounting system.

There are two main aspects of objective factors, first, natural disasters damage computer hardware, such as floods, fires, etc; second, man-made poor management caused by computer loss, information disclosure and so on. To avoid the occurrence of objective factors, can effectively improve the security performance of network accounting. Subjective factors also have two aspects, first, the user of the network accounting system security awareness of the existence of errors, they will be anti-virus software as a universal tool, in fact, anti-virus software does not prevent the invasion of computer hackers; second, the user network accounting System security technology does not understand, it is difficult to identify the way hackers invade the computer and can not effectively protect their own information security.

The paperlessness of network accounting avoids the accounting distortion of human factors, and the risk of distortion of accounting information is transferred to the network. The traditional 
accounting needs the seal of the enterprise and the clear economic responsibility to ensure the authenticity and scientificity of the accounting information, but the network accounting is due to the use of electronic vouchers, electronic books, etc., easy to leave traces of tampering. Many of the confirmation of network accounting are invalid, accounting information recipients will doubt the distrust of the suspect, at the same time, the accounting information transmission side will worry about whether the recipient can correctly identify and download.

The orderly and stable development of network accounting is inseparable from the perfect legal protection. The Bank of Bahrain was known as the "Queen's Bank of England", founded in 1763, with a wide range of operations and a great success in the international financial sector. The root cause of its failure is the Singapore Bahrain company futures manager Nick. Risen misjudged the direction of the Japanese stock market, the operation of computer financial investment, the use of its rich network of legal knowledge and self-view their own understanding of the bank in the financial aspects of the network loopholes try to take the law of the law of the neutral to obtain illegal interests. The main reason is that the development of computer accounting is not perfect, but the development of network accounting is not yet mature, and the evaluation standard of network accounting information associated with it is management mechanisms are not established. Causing some high-tech lawless elements or hackers to steal financial information, undermine the corporate financial system, resulting in an immeasurable loss of business economy, but it is difficult to bring them to justice.

\section{The Problem of Network Accounting Problems}

To solve the problem of computer network crime in foreign countries, China should draw lessons from it, formulate the current situation of network accounting in China, help to crack down on the laws and regulations of network accounting crime, strengthen the implementation of legislative work and promote our network The vigorous development of accounting for the development of Chinese network accounting to provide protection. As early as 1986, China has promulgated some laws and regulations on computer information security, but the network accounting, after all, and computer information security are different, China has not yet established a sound network accounting laws and regulations. The British government in 1983 has established a network of information security standards, the standard will be the computer network security level is divided into 4 and 8, and detailed description of the 4 level 8 level of each level of measurement. In 1995, the United States together with Europe to improve the network information security standards, to develop a common network of information security standards and for the shortcomings of network information put forward the relevant preventive measures. First of all, China should be based on Chinese national conditions, and secondly, with reference to the world's relevant network accounting has been established and applied effect of good laws and regulations, corporate network transactions standardization, for example, payment and accounting behavior, online sales and sales behavior, the disclosure of corporate responsibility and obligations, network accounting information security standards, network accounting management mechanism for detailed provisions, severe sanctions damage to computers and network accounting, and promote the good development of network accounting.

First, to take effective measures to protect the safety of the computer and the engine room environment, for example, the cost of high cost of computer hardware, to avoid the loss of computer hardware loss of network accounting information on the occurrence of the phenomenon; strict room management system, the job responsibilities, room operation matters, the engine room environment maintenance, etc., to prevent the occurrence of natural disasters.

Improve the internal control system of network accounting and for example, set the use of the computer permissions, input accounting information is correct, accounting information storage data security index and the overall system security system. Perfect internal control system of network accounting is conducive to prevent the internal staff due to moral corruption, the quality is not high harm, is conducive to control the risk of system resources, help reduce the destructive power of hackers invasion of the computer. 
The subjective factors that threaten the security of network accounting system are mainly due to the low awareness of the security of the network system and the user's network accounting security technology. Avoid the subjective factors on the network accounting system security damage can take the following measures: First, the computer's entire network system to take security precautions, the establishment of multi-level, abstract, comprehensive security system, for example, the computer internal system operation Personnel to strictly control the number and use of authority; Second, the computer implanted firewall technology and intrusion detection technology to effectively prevent hackers or viruses on the network accounting system invasion; Third, the network accounting system should be re-encrypted file processing, The landing information, for example, user name, date, use and password, etc., to strengthen the security performance of network accounting system. With the increasing progress of science and technology, improve the security performance of network accounting system will increase the way and enterprises should actively learn to reduce the loss caused by subjective factors.

Most of today's network accounting is used in the field of e-commerce. As the scope of e-commerce has been extended to various countries around the world, the network accounting is in urgent need of business knowledge, familiar with different national languages, and can quickly adapt to different social and cultural backgrounds. The transfer and processing of network accounting information depends on the network and computer technology, the network accounting practitioners of the computer technology level also need strict requirements. Therefore, there are plans, targeted to the existing or forthcoming accounting staff to carry out the basic knowledge of accounting theory, computer technology and network technology and other aspects of training, comprehensively enhance the overall quality of practitioners, fundamentally solve the high-end network Accounting for the lack of accounting talent for the country to develop suitable for the development of high-end network accounting talent.

\section{Conclusion}

There are still many drawbacks to the operation of network accounting. However, it is obvious that the advantages of traditional accounting are obvious, and only the problems existing in network accounting and the key mechanisms of network accounting and the corresponding measures are put forward. To play the advantages of network accounting, network accounting can effectively improve the efficiency of enterprises for enterprises to bring good economic returns.

\section{References}

[1] Li Chunxiao. Talking about the status quo, problems and countermeasures of network accounting[J]. Science and Technology Innovation and Productivity, 2015, 12: 43-44

[2] Xiao Hai. Analysis of network accounting problems and countermeasures[J]. Heilongjiang Foreign Trade, 2010, 04: 147-148.

[3] Gao Xiangqing. Network Accounting Development Problems and Preventive Measures [J] .Hubei Vocational and Technical College, 2012, 02: 90-92 + 109 